\title{
DIRECT METHOD OF ANALYSIS OF AN ISOTROPIC RECTANGULAR PLATE USING CHARACTERISTIC ORTHOGONAL POLYNOMIALS
}

\author{
F. 0. Okafor ${ }^{1, *}$ and 0. T. Udeh ${ }^{2}$ \\ 1, 2 DePARTMENT OF CiVIL ENGinEERING, UNIVERSITY OF NigERIA, NSUKKA. NIGERIA \\ E-mail addresses: 1 fidelis.okafor@unn.edu.ng, 2 ude.onyii@yahoo.com
}

\begin{abstract}
This work evaluates the static analysis of an isotropic rectangular plate with various boundary conditions. The direct variation method according to Ritz is used to obtain the total potential energy of the plate by employing the static elastic theory of plate. The shape function of fourth order for the plate under uniformly distributed load for various boundary conditions were formulated using the characteristic orthogonal polynomials (COP), which is also known as product of orthogonal strips of the plate along the two axes. Analyses of results obtained were compared with exact results presented in the monograph of Timoshenko and Woinowsky - Krieger. The previous work adopted shape function in the form of trigonometric series to solve the fourth order governing differential equation of the plate. This work is helpful for obtaining the shape functions not only for simply supported plates but also for rectangular plates with various kinds of support conditions, where the exact method presents intricate and complex solution. Finally, comparison has been done for the coefficients of deflection and moments at various aspect ratios of the plate for different support conditions. The results obtained by the use of the COP in the classical Ritz method are in close agreement with the results obtained from exact solutions from classical method.
\end{abstract}

Keywords: Thin Rectangular Plates, Ritz Direct Method, COP, Boundary Condition, Approximate solutions.

\section{INTRODUCTION}

Thin plates are common structural elements employed in many engineering applications and are subject to a wide variety of excitations, including acoustic excitations. The problem of a rectangular plate analysis is of great importance and many papers [1-5] have been devoted to the subject.

Cauchy and Poisson, were first to formulate the problem of plate bending based on general equations of theory of elasticity [1]. They obtained the governing differential equation for deflections that coincides completely with the well-known Germain - Lagrange equation. However, the first satisfactory theory of bending of plates is associated with Navier, who considered the plate thickness in the general plate equation as a function of rigidity. He also introduced an "exact" method, which transformed the differential equation into algebraic expressions by the use of Fourier trigonometric series [1].

Timoshenko and Woinowsky-Krieger [2], published a fundamental monograph that represented a profound analysis of various plate bending problems where Fourier trigonometric series were applied [2].
Trigonometric series can be used to formulate approximate shape function for a plate, whose four edges are simply supported or clamped. It can also be used for a plate whose opposite edges are clamped and the other opposite edges are simply supported [2]. However, it is extremely difficult to formulate a shape function for plates using trigonometric series when opposite edges are clamped and simply supported like propped cantilever beams. Examples of plates, whose shape function cannot be formulated using trigonometric series, include thin rectangular plate clamped on adjacent near edges and simply supported on adjacent far edges (SSCC), plate with all edges clamped with only a far short edge simply supported (SCCC), plate with all edges simply supported with one near short edge clamped (CSSS), plate with two edges simply supported with one edge clamped and the other fixed (SSCF), etc [3]. Some other boundary conditions make it difficult to use the trigonometric series [1, 4-5].

Nwoji [6] and Okonkwo [7] resorted to the use of element method plate bending problems. The FEM considers this continuum of a plate as an assembly of 
finite site particles and the overall response of such a system is obtained by formulating simultaneous algebraic equations that can be readily solved by a computer. If one is using element method, the more the number of elements used in the analysis the closer the approximate solution to the exact solution. Hence, when a plate has to be divided into several elemental plates for an accurate solution to be reached, then the extensive analysis is involved, requiring enormous time to be invested [3]. .

Baffah [8] analysed thin rectangualar isotropic plates by polynomials function using engergy method. Umeh [9] analysed both isotropic and orthotropic plates using spline functions. Polynomial method of Eigenvalue problem can effectively handle Eigen-value equations containing consistent mass. However, solution using Polynomial method becomes intractable when the size of the matrix is up to $4 \times 4$ [3].

Ventsel and Krauthermer [1], Ugural [4] and Okafor \& Oguaghamba [10] applied Ritz and Galerkin's methods to solve isotropic and orthotropic plate problems. Their results are very close to those exact solutions. The monographs by Timoshenko and Young, Den Hartog, Thompson [14] contains a comprehensive analysis and design considerations of free and forced vibrations of plates of various shapes. Vanam, B. C., Rajyalakshmi, M., \& Inala, R [15] used finite element method (FEM) with $4 \times 4$ mesh size to analyze an isotropic plate with hole. They equally presented a mat lab program and experimental results which they used to compare the result of plate deflection with exact solution results of different plate thickness

In this work, a comprehensive method is presented for the numerical solution of the thin rectangular plate's problem under uniformly distributed loads and different boundary conditions. The method is based upon the classical series expansion of polynomial to the fourth order and found to be easier and more effective.

\section{RITZ DIRECT VARIATIONAL METHOD IN THIN RECTANGULAR PLATE PROBLEM}

Ritz [11] Method belongs among the so-called direct variational methods that are commonly used. Direct methods application in thin rectangular plates provides solutions of deflections, forces, stresses, etc of the plate by employing conformable shape function to the minimum total potential energy of the plate only. It does not require the governing differential equation solution.

According to the Ritz [11] method, the deflection surface of the plate is approximated by a series of the form:

$$
w(x, y)=\sum C_{i} f_{I}(x, y)
$$

Where $f_{I}(x, y)$ are some coordinate functions that satisfy individually, at least, the kinematic boundary conditions and $\mathrm{C}_{\mathrm{i}}$ are unknown constants to be determined from the minimum potential energy principle.

Introducing the expression for $w(x, y)$ in the form of series into the total potential energy of a plate, we obtain after integrating the total potential energy over the surface area of the plate as a function of the unknown coefficients $\mathrm{C}_{\mathrm{i}}$ :

$$
\pi=\pi\left(K_{1}, K_{2}, K_{3}, \ldots K_{n}\right)
$$

Therefore, the extremum problem of the calculus of variations is transformed into the maximumminimum problem of differential calculus. The latter problem, in turn, is solved by satisfying the following:

$\frac{d \pi}{d K}=0, \quad \frac{d \pi}{d K_{2}}=0, \frac{d \pi}{d K_{3}}=0, \frac{d \pi}{d K_{n}}=0$

Equations (3) represent a system of linear nonhomogeneous algebraic equations for $\mathrm{K}_{\mathrm{i}}$. The solution of this system, being substituted into the expression of the shape function, yields a final solution of the problem shown in (4).

It is evident that the accuracy of the Ritz [11] method depends considerably on how well the assumed coordinate functions are capable of describing the actual deflection surface.

\section{CHARACTERISTIC ORTHOGONAL POLYNOMIALS SHAPE FUNCTIONS}

The assumed deflection shapes were normally formulated by inspection and sometimes by trial and error until Bhat [12] proposed a systematic method of constructing such functions in the form of COPs. The restrictions on the series are the following:

$$
K=\frac{b^{4} \int_{0}^{1} \int_{0}^{1} q \bar{w}(R, Q) \partial R \partial Q}{D \int_{0}^{1} \int_{0}^{1}\left[\left[\frac{1}{P^{4}}\left(\frac{\partial^{2} \bar{w}}{\partial R^{2}}\right)^{2}+\left(\frac{\partial^{2} \bar{w}}{\partial Q^{2}}\right)^{2}\right]+\frac{2 \mu \partial^{2} \bar{w}}{P^{2} \partial x^{2}} \cdot \frac{\partial^{2} \bar{w}}{\partial y^{2}}+\frac{2(1-\mu)}{P^{2}}\left(\frac{\partial^{2} \bar{w}}{\partial x \partial y}\right)^{2}\right] d R d Q}
$$


1. They satisfy the geometrical boundary conditions.

2. They are complete.

3. They do not inherently violate the natural boundary conditions.

When the above conditions are met, the numerical solutions converge to the exact solution and it depends also on the number of terms taken in the admissible series. Different series types, viz., trigonometric, hyperbolic, polynomial, give different results for the same number of terms in the series and the efficiency of the solution will depend to some extent on the type of series chosen [13].

According to Bhat [12], the displacement function for the rectangular plate is therefore assumed as a product of two functions; one of which is a pure function of $\mathrm{x}$ and the other is of $\mathrm{y}$ so that:

$$
\boldsymbol{W}(\boldsymbol{x}, \boldsymbol{y})=\boldsymbol{F}(\boldsymbol{x}) \cdot \boldsymbol{G}(\mathrm{y})
$$

This approach have been adopted by some authors [25] to propose the deflection function for plates. The Navier deflection function for SSSS is:

$$
\mathrm{W}(\mathrm{x}, \mathrm{y})=\sum_{\mathrm{m}=1}^{\infty} \sum_{\mathrm{n}=1}^{\infty} \mathrm{C}_{\mathrm{mn}} \operatorname{Sin}\left(\frac{\mathrm{m} \pi \mathrm{x}}{\mathrm{a}}\right) \operatorname{Sin}\left(\frac{\mathrm{n} \pi \mathrm{y}}{\mathrm{b}}\right)
$$

The Levy deflection function for SSSS is:

$$
w=w(x, y)=\sum_{m=1}^{\infty} G(y) \sin \frac{m \pi y}{a}
$$

Consider a rectangular plate of dimension, $\mathrm{a}$, along $\mathrm{x}$ axis and $b$, along $y$-axis. If the deflection pattern of the plate along $\mathrm{x}$ is represented by a beam strip qualitatively and the beam function is taken as $\mathrm{f}(\mathrm{x})$. Similarly, the corresponding beam function along $\mathrm{y}$ is taken as $\mathrm{G}(\mathrm{y})$.

The displacement function for the rectangular plate is therefore assumed as a product of two functions; one of which is a pure function of $\mathrm{x}$ and the other is of $\mathrm{y}$ so that Equation (5) is satisfied.

Expressing Equation (5) in the form of nondimensional parameters, say $\mathrm{R}$ and $\mathrm{Q}$ for $x$ and $y$ directions respectively, we obtain Equation (8.0) and (9.0).

$$
\begin{gathered}
\mathrm{x}=\mathrm{aR} ; \quad \mathrm{y}=\mathrm{bQ} ; \quad \mathrm{P}=\frac{\mathrm{a}}{\mathrm{b}} \text { and } \mathrm{a}=\mathrm{P} \\
\mathrm{w}(\mathrm{R}, \mathrm{Q})=F(\mathrm{R}) \cdot \mathrm{G}(\mathrm{Q})=\sum_{m=1}^{\infty} A_{m} \mathrm{R}^{m} \times \sum_{\mathrm{n}=1}^{\infty} \mathrm{B}_{\mathrm{n}} \mathrm{Q}^{\mathrm{n}} \\
=\sum_{\mathrm{m}=1}^{\infty} \sum_{n=1}^{\infty} A_{m} \mathrm{~B}_{\mathrm{n}} \mathrm{R}^{m} \mathrm{Q}^{\mathrm{n}}
\end{gathered}
$$

For a beam with an arbitrary support condition subjected to a uniformly distributed load along an arbitrary direction, it can be seen that due to this applied load, reactive forces such as, moments and reactions will develop at its supports and the deflection function for such a beam will be a fourth order function. This suggests that the polynomial of Equation (9) is a fourth order function. Expanding Equation (9) to $4^{\text {th }}$ series:

$$
\begin{aligned}
\mathrm{w}(\mathrm{R}, \mathrm{Q})=\sum_{\mathrm{m}=1}^{\infty} & \sum_{n=1}^{\infty} A_{m} \mathrm{~B}_{\mathrm{n}} \mathrm{R}^{m} \mathrm{Q}^{\mathrm{n}}=F(\mathrm{R}) \cdot \mathrm{G}(\mathrm{Q}) \\
& =\left(\mathrm{A}_{0}+\mathrm{A}_{1} \mathrm{R}+\mathrm{A}_{2} \mathrm{R}^{2}+\mathrm{A}_{3} \mathrm{R}^{3}\right. \\
& \left.+\mathrm{A}_{4} \mathrm{R}^{4}\right)\left(\mathrm{B}_{0}+\mathrm{B}_{1} \mathrm{Q}+\mathrm{B}_{2} \mathrm{Q}^{2}+\mathrm{B}_{3} \mathrm{Q}^{3}\right. \\
& \left.+\mathrm{B}_{4} \mathrm{Q}^{4}\right)
\end{aligned}
$$

The coefficients $A_{m}$ and $B_{n}$ of the series are determined from the boundary conditions at the edges of the plate. The shape functions are given in Table 1 for different boundary condition of plate.

\section{RITZ COEFFICIENTS, K, FOR PLATES OF DIFFERENT SUPPORT CONDITIONS}

Putting the Equations in Table 1 into the total potential energy equation for a thin rectangular isotropic plate under uniformly distributed lateral load, q, according to Ritz [11] Method (Equation (4)) at $\mu=0.3$, the following results given in Table 2 are established for the shape function coefficient, $\mathrm{K}$, for different support conditions.

\section{Table 1: Shape Functions for Different Boundary Conditions of Plate}

\begin{tabular}{lcc}
\hline S/No & $\begin{array}{c}\text { Support } \\
\text { Condition }\end{array}$ & Deflected Shape Function \\
\hline 1. & SSSS & $W(R, Q)=K\left(R-2 R^{3}+R^{4}\right)\left(Q-2 Q^{3}+Q^{4}\right)$ \\
2. & CCCC & $W(x, y)=K\left(R^{2}-2 R^{3}+R^{4}\right)\left(Q^{2}-2 Q^{3}+Q^{4}\right)$ \\
3. & CSSS & $W(R, Q)=K\left(R-2 R^{3}+R^{4}\right)\left(1.5 Q-2.5 Q^{3}+Q^{4}\right)$ \\
4. & CCSC & $W(R, Q)=K\left(\mathrm{R}^{2}-2 \mathrm{R}^{3}+\mathrm{R}^{4}\right)\left(1.5 Q-2.5 Q^{3}+Q^{4}\right)$ \\
5. & CSCS & $W(x, y)=K\left(\mathrm{R}-2 \mathrm{R}^{3}+\mathrm{R}^{4}\right)\left(Q^{2}-2 Q^{3}+Q^{4}\right)$ \\
6. & CCSS & $W(R, Q)=K\left(1.5 R-2.5 R^{3}+R^{4}\right)\left(1.5 Q-2.5 Q^{3}+Q^{4}\right)$ \\
\hline
\end{tabular}


Table 2: $K$-Values for Shape Functions for Different Boundary Condition of Plate

\begin{tabular}{lcc}
\hline S/no & $\begin{array}{c}\text { Support } \\
\text { Condition }\end{array}$ & K-value for deflected shape function \\
\hline 1 & SSSS & $\frac{q b^{4}}{D}\left[\frac{\mathrm{P}^{4}}{5.90476+5.90476 \mathrm{P}^{4}+11.7959 \mathrm{P}^{2}}\right]$ \\
2 & $\mathrm{CCCC}$ & $\frac{q b^{4}}{D}\left[\frac{\mathrm{P}^{4}}{1.14282+1.14282 \mathrm{P}^{4}+0.65304 \mathrm{P}^{2}}\right]$ \\
3 & $\operatorname{CSSS}$ & $\frac{q b^{4}}{D}\left[\frac{\mathrm{P}^{4}}{1.8095+4.42855 \mathrm{P}^{4}+762.9900 \mathrm{P}^{2}}\right]$ \\
4 & $\operatorname{CCSC}$ & $\frac{q b^{4}}{D}\left[\frac{\mathrm{P}^{4}}{2.4127+1.14282 \mathrm{P}^{4}+241.3066 \mathrm{P}^{2}}\right]$ \\
5 & $\operatorname{CSCS}$ & $\frac{q b^{4}}{D}\left[\frac{\mathrm{P}^{4}}{1.14285+5.90475 \mathrm{P}^{4}+2.77545 \mathrm{P}^{2}}\right]$ \\
6 & $\operatorname{CCSS}$ & $\frac{q b^{4}}{D}\left[\frac{P^{4}}{2.4126+2.4126 \mathrm{P}^{4}+126962.2222 \mathrm{P}^{2}}\right]$ \\
\hline
\end{tabular}

\section{RESULTS AND DISCUSSION}

The design factors $\alpha$ and $\beta$ for deflection and bending respectively of rectangular plates at varying aspect ratio, p, are obtained using equations (Tables 1 and 2) as given in the previous sections at the centre of the plate. Various rectangular plates boundary conditions such as, all round simply supported plate (SSSS), all round clamped rectangular plate (CCCC), rectangular plate clamped on two opposite short edges and simply supported on two opposite long edges (CSCS) are considered and results compared with exact solution presented by Timoshenko and Woinowsky-Krieger [2].
Figures 1 through 3 are the curves of design factors $\alpha$, $\beta_{\mathrm{x}}$ and $\beta_{\mathrm{y}}$. They present good interpretations of the two results.

From Figure 1, it is clear that the results obtained herein agree very well with that of exact solution by Timoshenko and Woinowsky-Krieger [2]. The disparity between the two curves or an average percentage difference of $7.0181 \%$ is very negligible. Hence, the approximating function according to the characteristic orthogonal polynomial can be used in confidence for analysis of deflection of a plate with all edges simply supported.

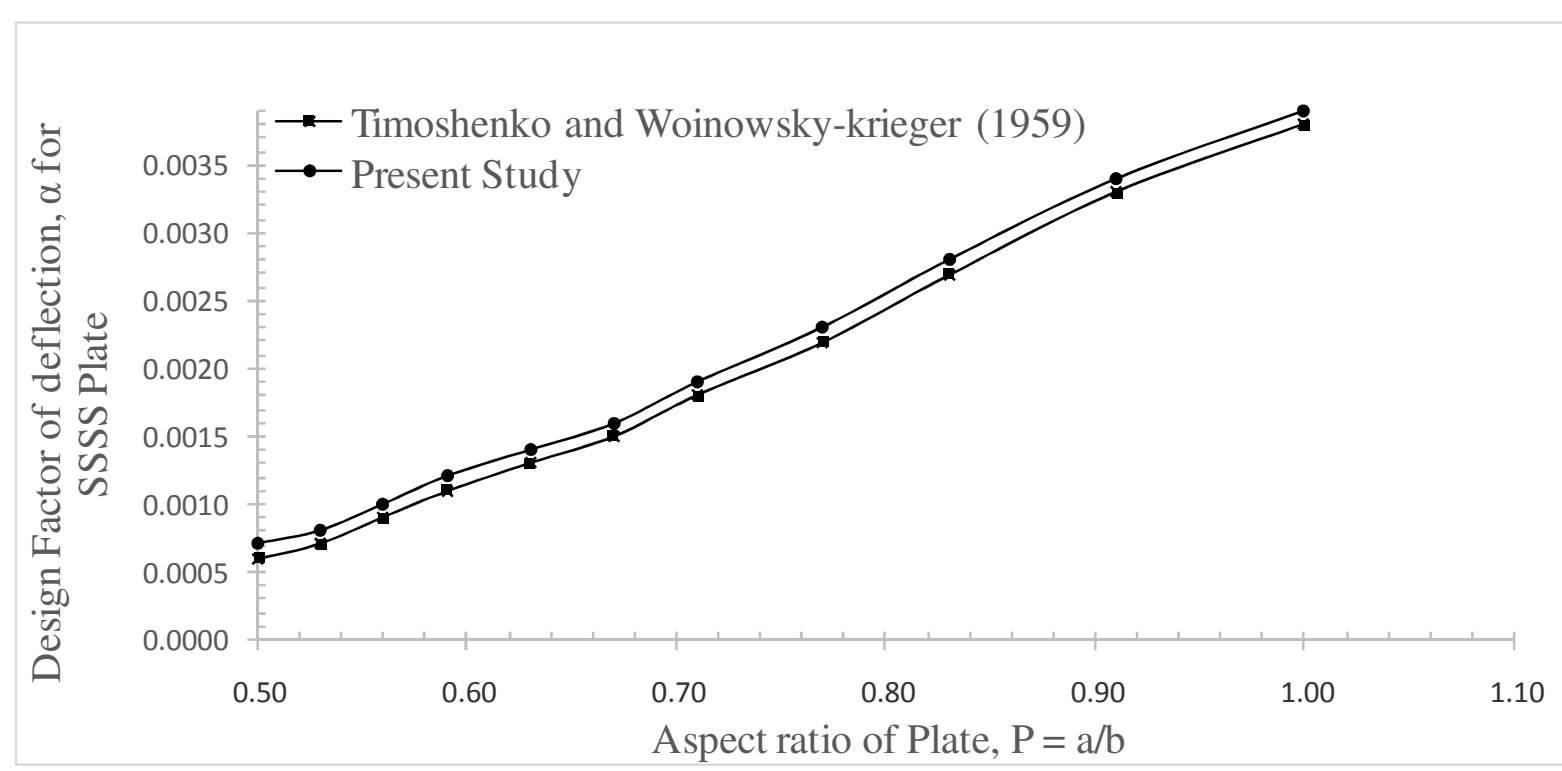

Figure 1: Relationship Between Design Factor $\alpha$, Against Aspect Ratio, P for Plate SSSS 


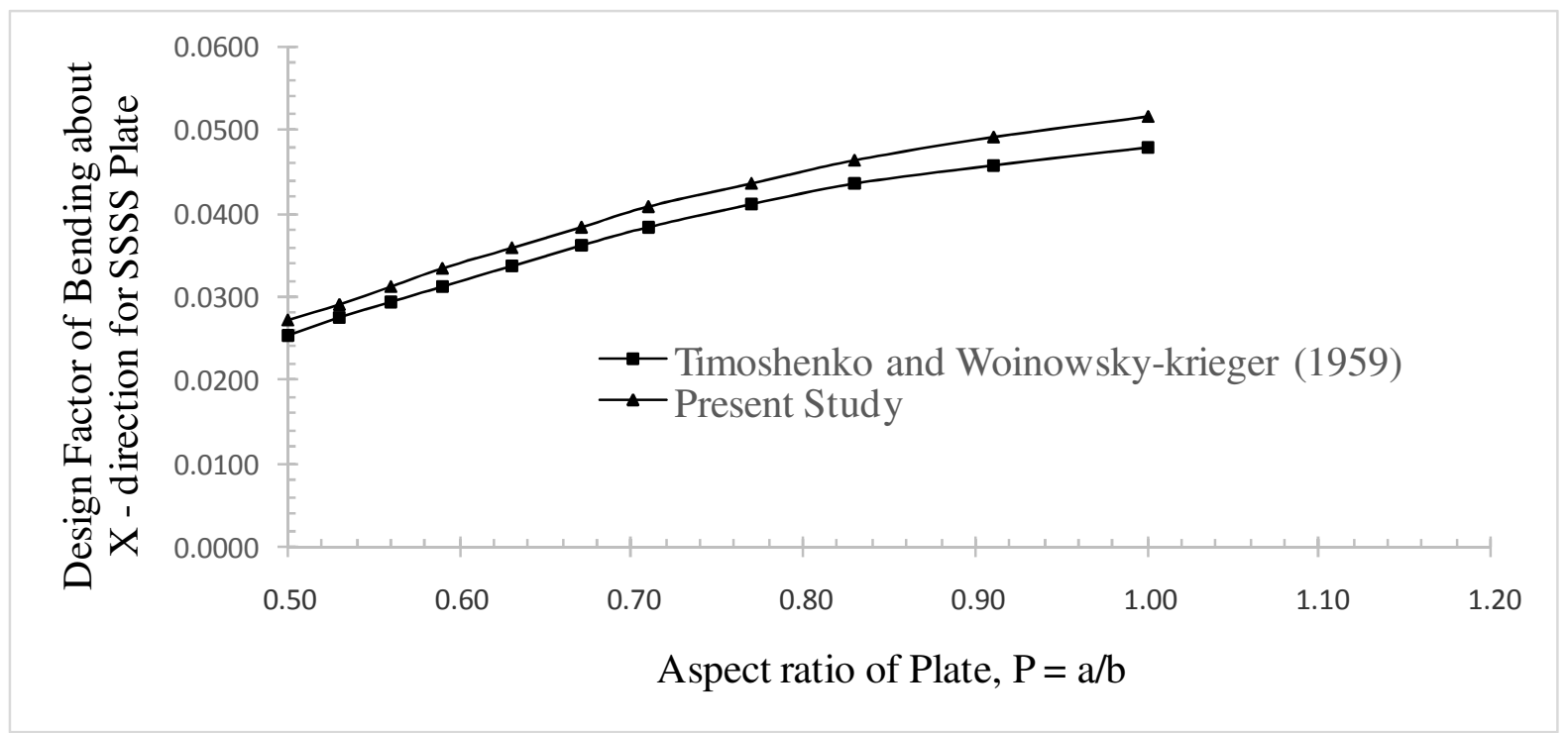

Figure 2: Relationship Between Design Factor $\beta_{x}$, Against Aspect Ratio, P for Plate SSSS

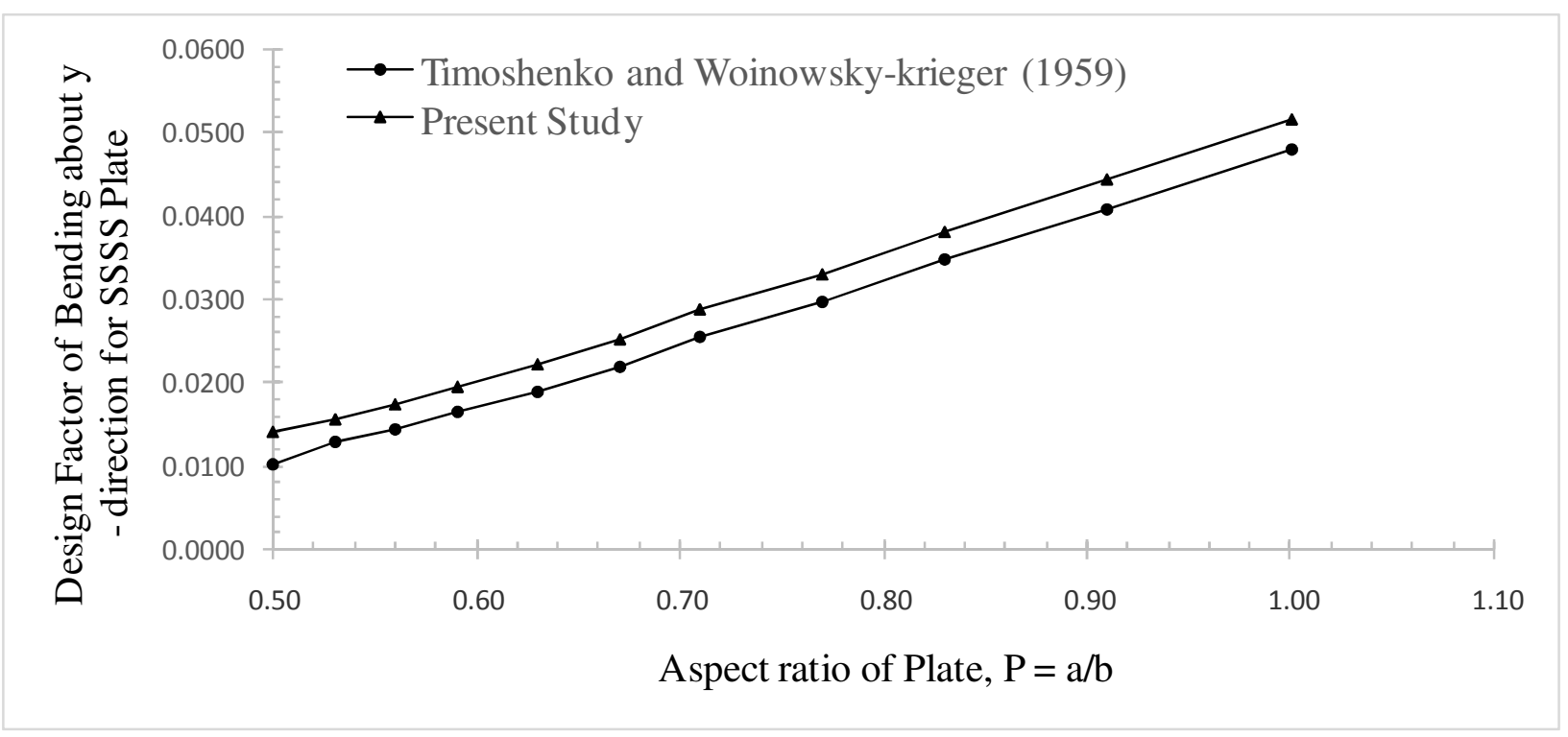

Figure 3: Relationship Between Design Factor $\beta_{y}$, Against Aspect Ratio, P for Plate SSSS

Figures 2 and 3 equally validates these COP functions for rectangular plates analysis. Though the disparity between the curves in bending is obvious. It does not invalidate the results, since the values from the present solution are upper bound results, which will not put the structure being designed in danger. Hence, the approximating function according to characteristic orthogonal polynomial can be used reliably for analysis of a plate with all edges simply supported. Figures 4 through 6 are the curves of design factors $\alpha$, $\beta_{\mathrm{x}}$ and $\beta_{\mathrm{y}}$. They present good interpretations of the two results.

From Figure 4, it can be seen that the results obtained in this work agree very well with that of exact solution by Timoshenko and Woinowsky - Krieger [2]. The disparity between the two curves or an average percentage difference of $7.7867 \%$ is very negligible. Hence, the approximating function according to the characteristic orthogonal polynomial can be used in confidence for analysis of deflection of a plate with all edges clamped. 


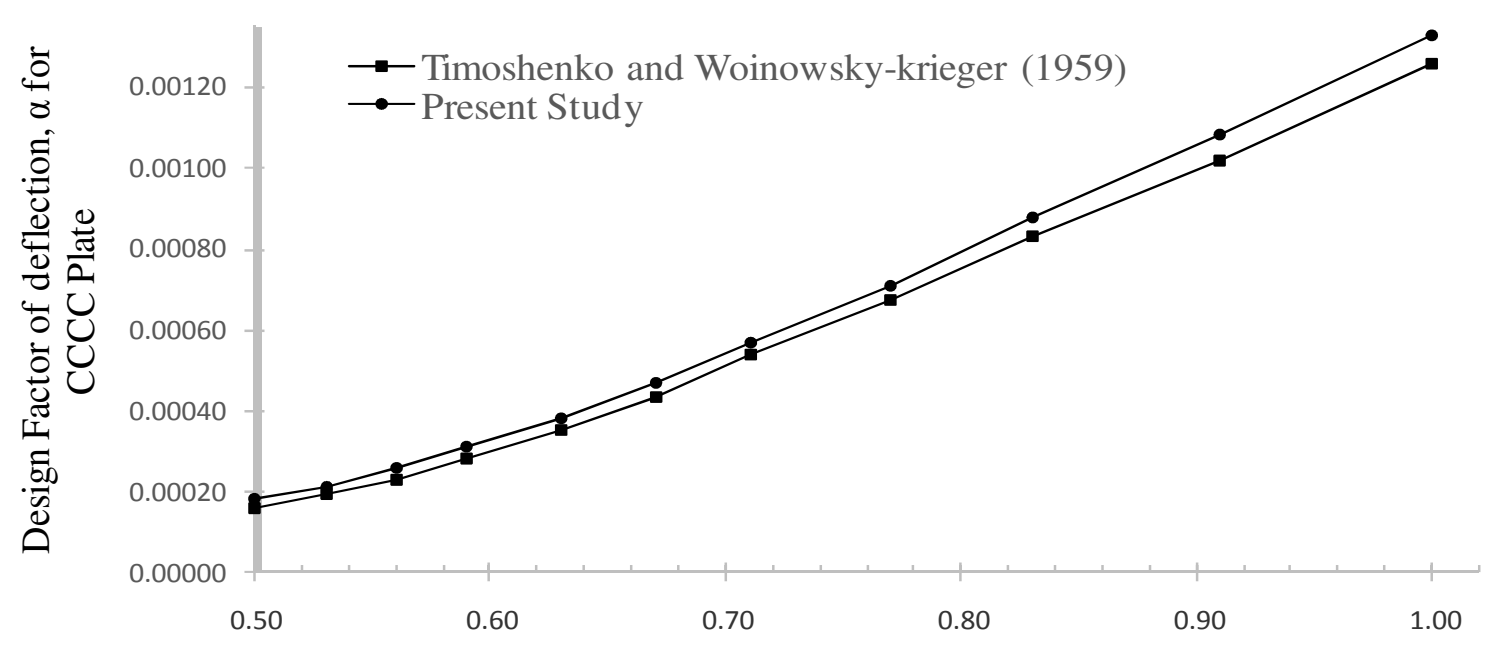

Aspect ratio of Plate, $\mathrm{P}=\mathrm{a} / \mathrm{b}$

Figure 4: Relationship Between Design Factor $\alpha$, Against Aspect Ratio, P for Plate CCCC

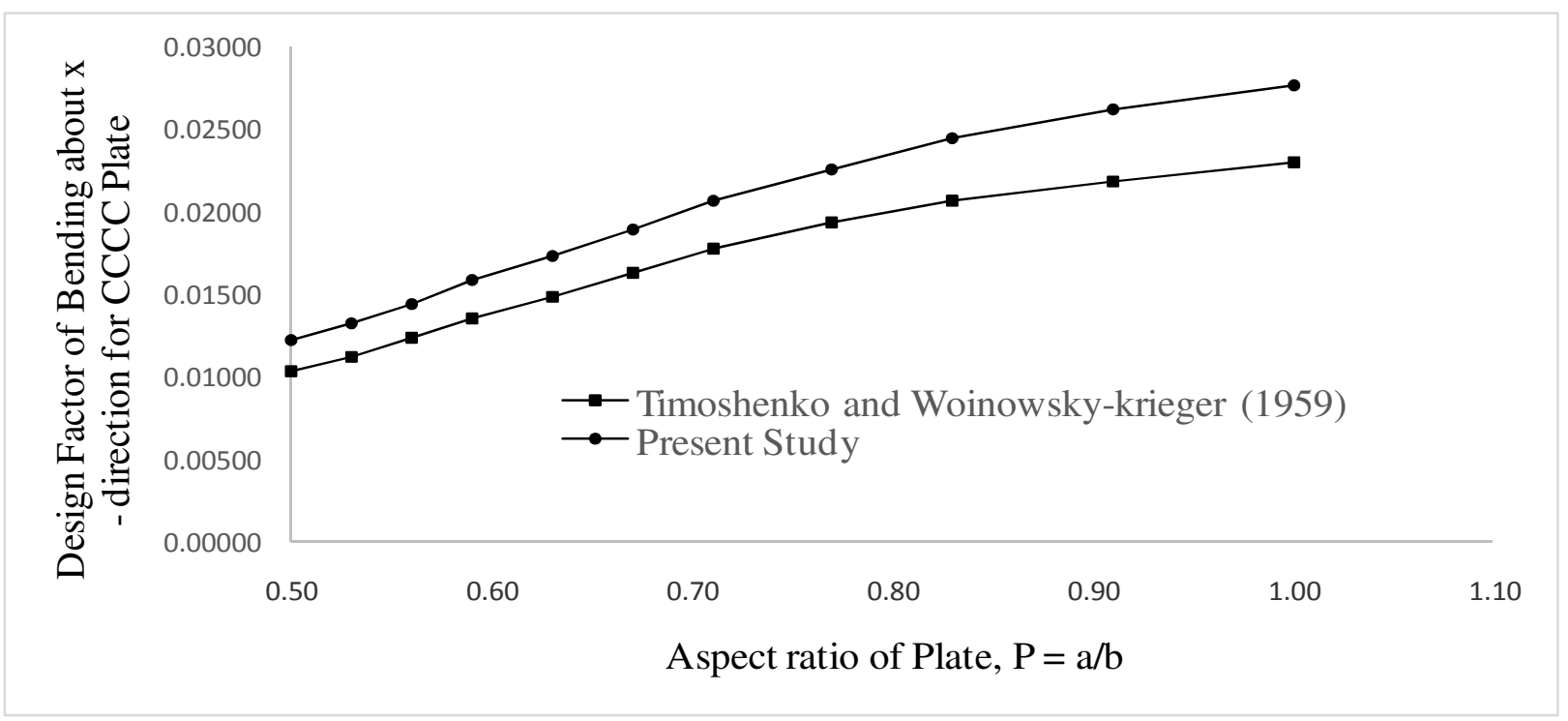

Figure 5: Relationship Between Design Factor $\beta_{x}$, Against Aspect Ratio, P for Plate CCCC

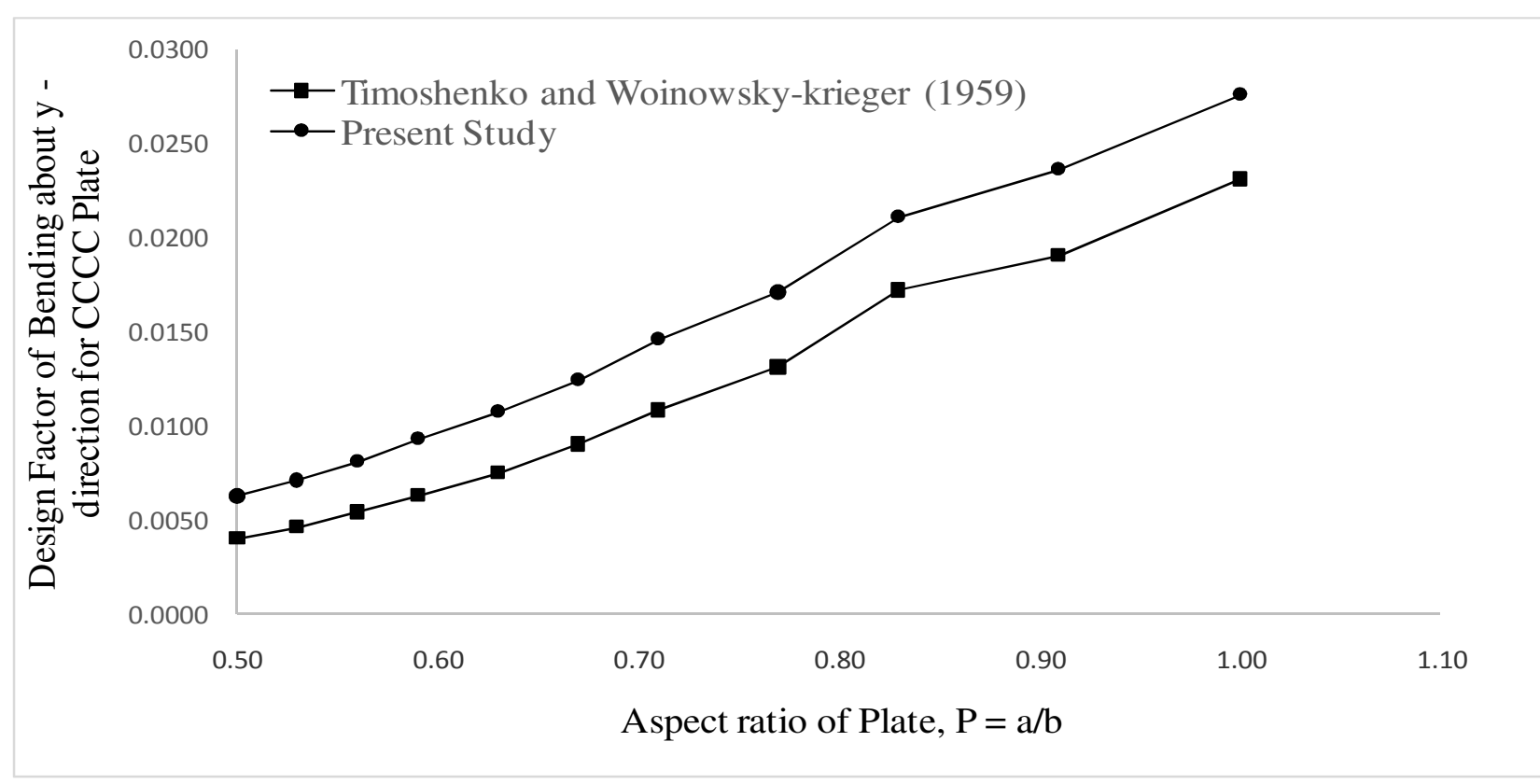


Figures 5 and 6 equally validates these COP functions for rectangular plates analysis. Though the disparity between the curves in bending is obvious. It does not invalidate the results, since the values from the present solution are upper bound results, which will not put the structure being designed in danger.

Hence, the approximating function according to characteristic orthogonal polynomial can be used reliably for analysis of a plate with all edges clamped.

Figures 7 through 9 are the curves of design factors $\alpha$, $\beta_{\mathrm{x}}$ and $\beta_{\mathrm{y}}$. They present good interpretations of the two results.

From Figure 7, it can be seen that the results obtained in this work agree very well with that of exact solution by Timoshenko and Woinowsky - Krieger [2].

The disparity between the two curves is very negligible. Hence, the approximating function according to the characteristic orthogonal polynomial can be used in confidence for analysis of deflection of a plate clamped on two opposite short edges and simply supported on two opposite long edges. The missing result in the figure indicates the paucity of literature for such a plate.

Figures 8 and 9 equally validates these COP functions for rectangular plates analysis, as the behavior of the two solutions are relatively parallel to one another. The missing result in the figure indicates the paucity of literature for such a plate.

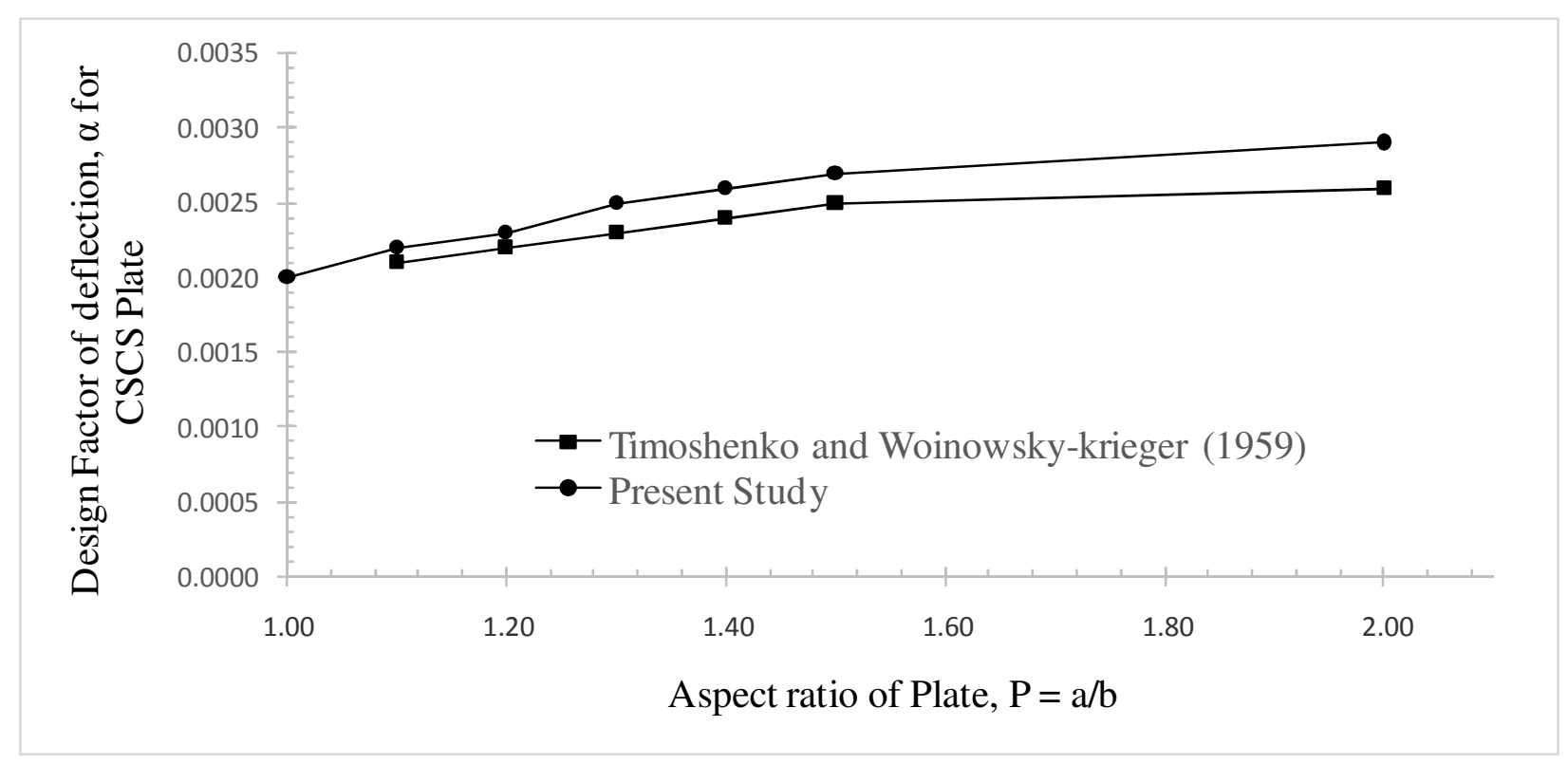

Figure 7: Relationship Between Design Factor $\alpha$, Against Aspect Ratio, P for Plate CSCS

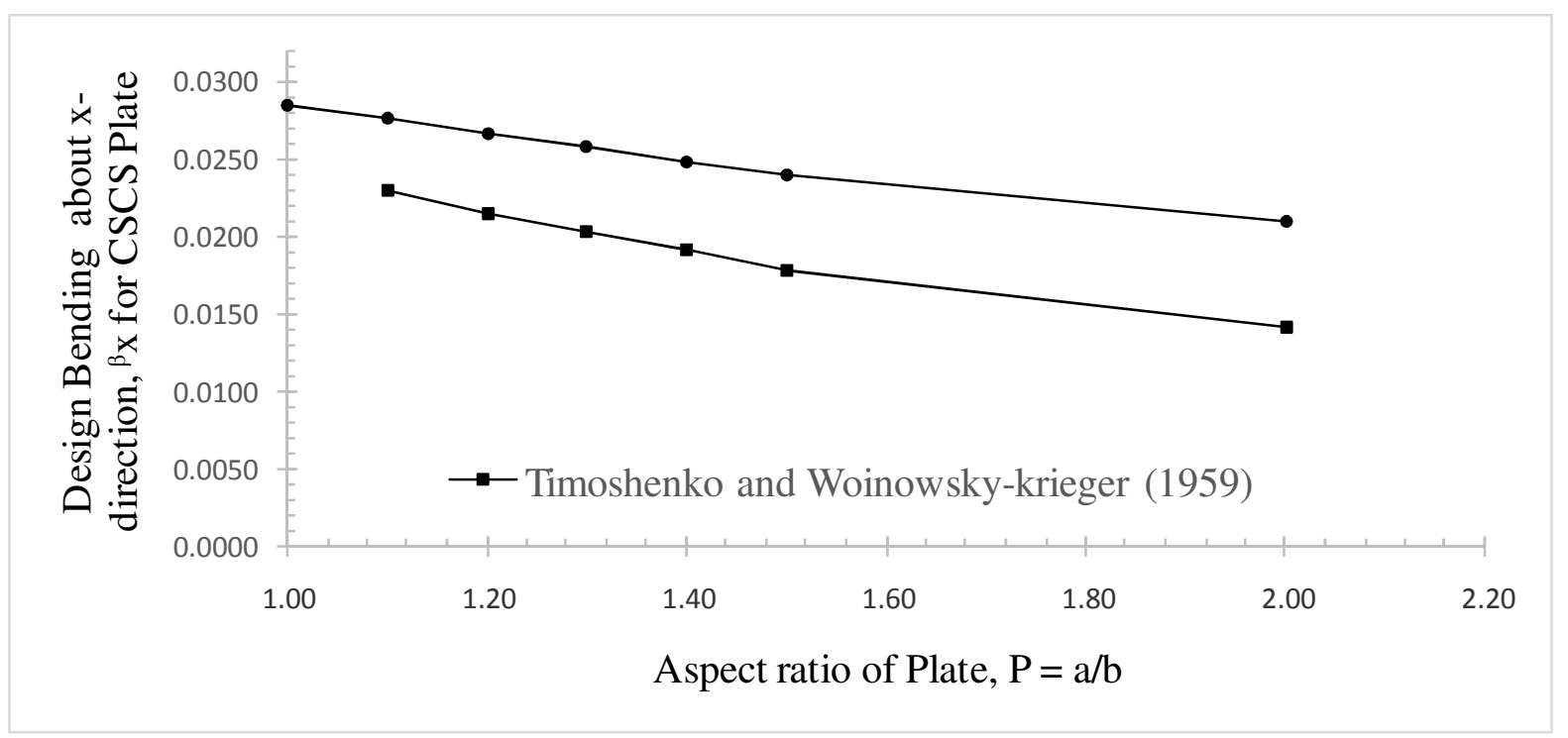

Figure 8: Relationship Between Design Factor $\beta_{x}$, Against Aspect Ratio, P for Plate CSCS 


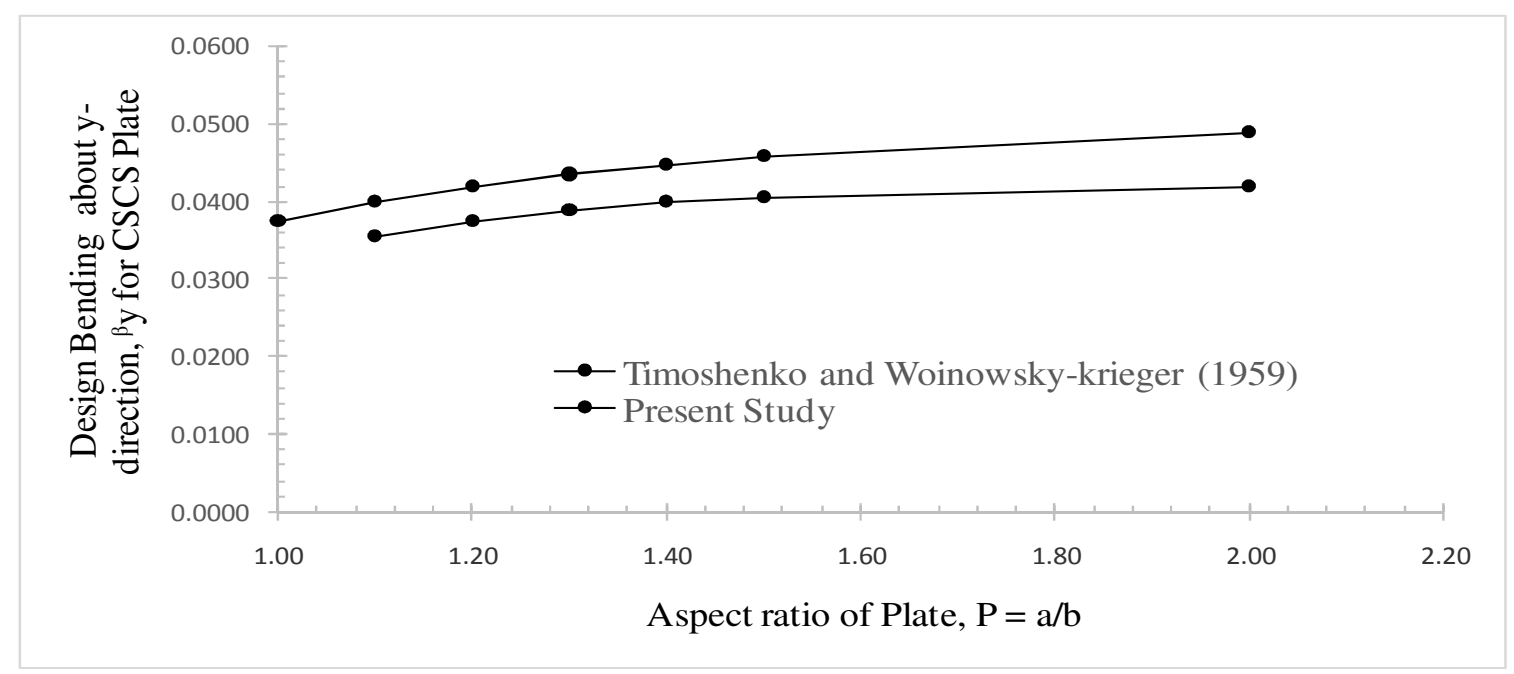

Figure 9: Relationship Between Design Factor $\beta_{y}$, against Aspect Ratio, P for Plate CSCS

\section{CONCLUSIONS}

Based on the results of this work, the following conclusions could be drawn:

i. Characteristic orthogonal polynomial based derived shape functions for rectangular plates are satisfactory in approximating the deformed shape of thin rectangular plates of various boundary conditions.

ii. Direct variation principle (based on Ritz method) can be used in confidence to satisfactorily analyze real time rectangular thin plates of various boundary conditions under lateral loadings.

iii. The results obtained herein are very close to the exact results obtained by previous research work that used trigonometric method of analysis of plates.

\section{REFERENCES}

[1] Ventsel, E., \& Krauthammer, T. (2001). Thin Plates and Shells: Theory, Analysis and Applications. New York: Maxwell Publishers Inc.

[2] Timoshenko, S. P., \& Woinowsky - Krieger, S. (1959). Theory of Plates and Shells (2nd ed.). Auckland: McGraw-Hill Inc.

[3] Ibearugbulem, O. M. (2012). Application of a Direct Variational Principle in Elastic Stability Analysis of Thin Rectangular Flat Plates. PhD Thesis Submitted to School of Postgraduate Studies, Federal University of Technology owerri.

[4] Ugural, A. C. (1999). Stresses in Plates and Shells (2nd Edition ed.). Singapore: McGraw-Hill.

[5] Iyengar, N. G. (1988). Structural Stability of Columns and Plates. New York: Ellis Horwood Limited

[6] Nwoji C. U. (1985). Analysis of Ribbed and Grid Plate using Finite Element Method. Nsukka: M.Eng
Thesis Submitted to School of Postgraduate Studies, University of Nigeria Nsukka.

[7] Okonkwo G. (2011). Application of Classical Finite Strip Method in Analysis of Rectangular Plate: M.Eng Thesis Submitted to School of Postgraduate Studies, University of Nigeria Nsukka.

[8] Baffah E. J. (2007). Analysis of thin rectangular plate by polynomial function using energy method. Phd Thesis Submitted to School of Postgraduate Studies, University of Nigeria Nsukka.

[9] Umeh C. (1996). Analysis of Isotropic or Orthotropic Plates Using Spline Function. M.Eng Thesis Submitted to School of Postgraduate Studies, University of Nigeria Nsukka.

[10] Okafor, F. O., \& Oguaghamba, O. (2009). Effects of Flexural Rigidity of Reinforcement Bars on the Fundamental Natural Frequency of Reinforced Concrete Slabs. Nigerian Journal of Technology, Vol. $28(2)$, pp 48 - 57.

[11] Ritz, W. (1909). Theorie der Transversalschwingungen einer quadratischen Plattemit freien randern. Ann. Phys., Vol. 28, pp. 737 - 786.

[12] Bhat, R. B. (1985a). Natural Frequencies of Rectangular Plates using Characteristic Orthogonal Polynomials in Rayleigh - Ritz Method. Journal of Sound and Vibration, Vol. 102 (4), pp 493 - 499.

[13] Brown, R. E., \& Stone, M. A. (1997). On the use of polynomial series with the Rayleigh Ritz. Composite Structures, Vol. 39 (3 - 4), pp 191 - 196.

[14] Weaver, W., Timoshenko, S. P., \& Young, D. H. (1989). Vibration Problems in Engineering (5th ed.). New York: John Wiley \& Sons.

[15] Vanam, B. C., Rajyalakshmi, M., \& Inala, R. (2012, April). Static Analysis of an Isotropic Rectangular Plate Using Finite Element Analysis (FEA). Journal of Mechanical Engineering Research , pp. 148 - 142. 